\title{
Analysis on the financing Status of New Agricultural Business Entities Based on the Perspective of Rural Revitalization-Take Lanxi City, Zhejiang Province as An Example
}

\author{
Xichen Huang \\ School of Economics and Management, Zhejiang Ocean University, Zhoushan 316022, Zhejiang, China
}

\begin{abstract}
As a traditional agricultural country, the Third Session of the Thirteenth National People's Congress clearly stated that it should vigorously support the development of new rural agricultural business entities. With the proposal of the rural revitalization strategy, conditions have been provided for the development of this emerging group. This article takes rural revitalization as a perspective, taking Lanxi City, Zhejiang Province as an example. From the perspectives of new business entities, banks and other financial institutions, and government policies, the current situation of financing of new agricultural business entities is analyzed. On this basis, it puts forward feasible suggestions that are in line with the local area, hoping to give new enlightenment to modern agriculture and rural revitalization.
\end{abstract}

Keywords: Rural revitalization, New type of agricultural business entity, Financing status, Financing advice.

\section{Introduction}

According to data, various new agricultural business entities such as family farms, farmers' professional cooperatives, and leading agricultural industrialization enterprises are competing to develop[1], with a total of more than 3 million. Taking Lanxi City, Zhejiang Province as an example, the city's new agricultural business entities have realized the transformation from nothing to strong. In 2018, there were 801 registered farmers' professional cooperatives, 793 family farms, and 77 leading agricultural enterprises above the municipal level, and the demand for financing increased significantly. At the same time, affected by factors such as the weak nature of the agricultural industry, the slow development of the financial market, and the need to strengthen policy support, many new agricultural business entities have no effective directions and methods in the financing process, which will seriously restrict the sustainable health of modern agriculture develop.

\section{An Analysis of the Current Financing Status of the New Type of Agricultural Management}

Lanxi City is located in the hilly area of central and western Zhejiang, and belongs to Jinhua City, Zhejiang Province. As a traditional agricultural city, it is one of the counties and cities with the most geographical indication agricultural products in the whole province. In 2019, the city's cumulative total output value of agriculture, forestry, animal husbandry and side-fishing was 4.55 billion yuan, with an added value of 2.67 billion yuan, ranking first in Jinhua. The total sown area of crops for the year was 574,700 mu2. The level of agricultural modernization has continued to improve. A total of 45,400 mu of high-standard farmland has been newly built throughout the year, and the level of agricultural mechanization has reached 75.25\%3. Since August 2019, it has successively undertaken the Ministry of Agriculture and Rural Affairs in Zhejiang Province's only "Political and Bank-Responsible Financial Support Agriculture Service System and Risk Dispersion Mechanism Innovation Pilot" and the province's "Grassroots Policy-based Agricultural Credit Guarantee Service Innovation Pilot", Although Lanxi City's new agricultural business entities still have certain financing difficulties, they have made breakthroughs. Taking Lanxi's new agricultural business entities as a sample, the research results can be used for reference. The study found that the current financing situation presents the following characteristics.

\subsection{Insufficient Endogenous Financing}

The new agricultural business entity relied heavily on endogenous financing during its initial stage. On the one hand, the financing information of new agricultural business entities is asymmetric in the early stage of development, and the early stage mainly relies on initial endogenous financing. Therefore, in the initial stage of entrepreneurship, most of them rely on their own operations to accumulate profits. During the investigation process, most of the initial capital of the new agricultural business entities in Lanxi came from part-time operations and migrant workers. However, internal funds still need to be used for daily family support, which cannot meet the needs of long-term operations and scale-up. In severe cases, many new agricultural business entities will go bankrupt due to insufficient funds.

On the other hand, when the new agricultural business entity enters the growth and maturity stage, several major products will be gradually formed, and the profit level will gradually stabilize but weaken. At this stage, the ability of enterprises to accumulate capital is severely restricted. 


\subsection{Single External Financing Channel}

After the new agricultural business entities cannot meet their normal operations with their own funds, external financing has become the main method of corporate financing. However, the single external financing channel has aggravated the financing difficulties of the new agricultural business entities. On the one hand, compared with other industries such as manufacturing, agriculture has relatively low benefits and needs to bear the dual risks of nature and the market. Due to the high financial risks, investors lack confidence in it. Therefore, it is difficult for new agricultural business entities such as family farms to obtain funds through the issuance of bonds.

On the other hand, from a nationwide perspective, since listing indicators are mainly used to support state-owned large and medium-sized enterprises, it is difficult for ordinary new agricultural business entities to meet the listing qualification requirements. As of the end of March 2020, only 12 and 32 agricultural companies have been successfully listed on the ChiNext and SME boards, respectively, and only 111 agricultural companies have been successfully listed on the NEEQ, and the ability to raise funds is very limited4. Under the influence of the above circumstances, most of the new agricultural business entities still rely on bank credit as a single source of funds.

\subsection{Financing Costs have been Reduced}

Corporate financing costs include interest expenses and fund-raising expenses. Therefore, compared with large-scale enterprises, new agricultural business entities not only cannot enjoy preferential interest rates when borrowing, but the inevitable guarantee costs and overly complicated application procedures in the loan process will pay more transaction costs[2].

In order to reduce the financing cost of enterprises, agricultural entities in the Lanxi area can apply for a regional exclusive "Golden Agricultural Loan" to obtain a 1.5\% discount loan for financing loans. This policy makes the loan interest rate of agricultural enterprises lower than other enterprises. However, as of May 2020, only 750,000 yuan of discount loans have been completed, failing to cover most of the new agricultural business entities. Aiming at the problems of the agricultural industry with few fixed assets, insufficient collateral, and long and cumbersome application time. Through the superimposed effect of the production interest discount policy and policy guarantee services, the annual guarantee fee is reduced from a minimum of $0.8 \%$ to a minimum of $0.5 \%$. At the same time, the loan time is shortened. The fastest loan time is 4 days, with an average of 10 days. However, due to the limited coverage area, most new agricultural business entities will still bear more guarantee fees, mortgage asset evaluation fees and other expenses, which will also increase the financing costs of new agricultural business entities. Similarly, when the above-mentioned borrowing methods cannot be satisfied, private borrowing has to be chosen. And this will undoubtedly continue to increase the difficulty and cost of financing new agricultural business entities.

\section{An Analysis of the Causes of the Financing Status Quo of the New Type of Agricultural Management}

\subsection{From the Perspective of New Agricultural Management}

\subsubsection{Expansion of business entities}

Different from traditional agriculture, the new agricultural business entity represents the most advanced agricultural productivity. It has obvious advantages in information, production technology, and market development. Its profitability, capital turnover rate, and debt solvency are two or three times that of traditional agriculture. However, large-scale, industrialized, and intensive management models often require a large investment of funds to purchase a large number of agricultural inputs, agricultural machinery and equipment, and to learn advanced production technologies[3]. For example, the Zhejiang Xiyan Ecological Agriculture Park Project, Lanxi Huatong Animal Husbandry Breeding Base, Zhejiang Lanxi Zhuanyan Torreya Industrial Base, Zhuge Caotang Modern Agricultural Science and Technology Park and other projects have invested more than 100 million yuan, and financing needs have exceeded farmers' microfinance. Scope, the demand for large amounts of funds is very prominent. Relying on the accumulation of the enterprise itself is far from enough, and it is extremely easy to get into financing difficulties.

\subsubsection{Various systems of business entities are not sound}

Most of the professional farmer cooperatives in Lanxi City aim to obtain support funds and preferential policies. The cooperatives are loosely managed and have not yet formed a "risk-sharing and benefit-sharing" linkage mechanism; most of the family farms are family-run "mom-and-pop shops" that have not been established. Financial system and modern management system; at the same time, the threshold for the establishment of new agricultural business entities is low, and some only need to go through industrial and commercial registration. Therefore, due to the small scale, the relatively low overall quality of the operators and the incomplete various systems, there is a lack of publicly recognized financial statements and operating records. On the one hand, operators cannot reach the financial access threshold and limit financial support. On the other hand, the information asymmetry between banks and enterprises will further increase the difficulty of bank review, lending, and supervision.

\subsubsection{Still lacks effective collateral}

New agricultural business entities usually focus on biological assets, with fewer collaterals. First of all, in the trial process of the "two-right mortgage", the conditions are ripe for the full introduction of agricultural land mortgage loans, but due to 
difficulties in circulation and disposal, the rural housing mortgage loans have not yet formed a closed loop and cannot be fully promoted. It is reported that Lanxi Rural Commercial Bank provides farm house mortgage business, but the loan amount is small, mostly only 50,000 yuan. Secondly, from a nationwide perspective, the construction of credit loans takes a relatively short time, the rural financial ecological environment is lagging, some farmers have weak financial awareness, and untrustworthy behaviors such as defaulting on loans and defrauding loans occur from time to time. It can be seen from Table 1 that the highest proportion of non-performing loans of commercial banks is in wholesale and retail businesses, followed by agriculture, forestry, animal husbandry and fishery, and wholesale and retail businesses often include many agricultural business entities. Finally, "patent loans" and "brand loans" cannot be applied to start-up business entities. Therefore, the lack of effective collateral substantially increases the difficulty and cost of corporate financing.

Table 1: Statistics of non-performing loans of commercial banks by industry in 2015 (unit: 100 million yuan, \%)

\begin{tabular}{|c|c|c|}
\hline Industry & $\begin{array}{c}\text { Non-perform } \\
\text { assets }\end{array}$ & $\begin{array}{c}\text { Proportion of } \\
\text { non-performing } \\
\text { loans }\end{array}$ \\
\hline Agriculture, forestry, husbandry and fishery & 636.5 & 3.53 \\
\hline Mining & 438.6 & 2.33 \\
\hline Manufacturing & 4298.2 & 3.35 \\
\hline $\begin{array}{l}\text { Production and supply of electricity, heat, } \\
\text { gas and water }\end{array}$ & 117.2 & 0.37 \\
\hline Construction & 458.5 & 1.39 \\
\hline Wholesale and retail & 3997.7 & 4.25 \\
\hline Transportation, storage and postal services & 335.1 & 0.58 \\
\hline Accommodation and catering & 169.6 & 2.26 \\
\hline $\begin{array}{l}\text { Information transmission, software and } \\
\text { information technology services }\end{array}$ & 41.8 & 1.06 \\
\hline Finance & 13.2 & 0.19 \\
\hline
\end{tabular}

3.2 From the Perspective of Banks and Other Financial Institutions

\subsubsection{The financing threshold is too high}

At present, the entry barriers in my country's capital market are very high, and new agricultural business entities in the initial growth stage can hardly obtain funds from the capital market. By comparing the A-share and ChiNext IPO methods, we can see that the conditions for listing on ChiNext and Main Board are almost the same, except that the net profit, operating income and other indicators are lowered. In order to prevent systemic risks, the regulators for the time being, I dare not easily lower the threshold of the capital market. At the same time, under the influence of domestic and foreign economies, banks have increased their loan requirements in order to protect their own interests in order to avoid risks. In recent years, a reasonable distribution method, a sound financial system, and the ability to independently assume external debt are the basic requirements of most agricultural loans. This type of behavior further raises the financing threshold for new agricultural business entities.

\subsubsection{Commercial banks pursue economies of scale}

For commercial banks, loans from new agricultural business entities cannot form economies of scale. Compared with large-scale enterprises, the number of loans required by the new agricultural business entities is relatively small, but the procedures and links experienced by the loans are not much different. Its operating mechanism virtually increases the operating cost of the bank. For this purpose, financial institutions are not willing to support agriculture and the follow-up investment in agriculture-related loans is insufficient. Although the number of various state-owned banks, commercial banks, and rural commercial banks in Lanxi City is considerable, and many policies have been issued to support the financing and development of new agricultural business entities. But generally speaking, agriculture is a self-organizing mechanism that requires continuous input and seasonal differences in input and output, and lacks continuous service[4].

\subsubsection{Lack of specialized financial services institutions}

For my country's current financial system, there is a lack of financial institutions that specialize in serving new agricultural business entities. Although banks such as rural credit cooperatives are spread all over the country, they are the main force of agriculture-related loans. However, due to its short development time and irregularities, it has a large demand for funds. They are more inclined to township industrial enterprises or agricultural materials industries, and their assistance to new agricultural business entities is limited. Emerging commercial banks, such as city commercial banks, also blocked the financing of new agricultural business entities due to factors such as funds, service levels, and projects. The services of some regional financial institutions and large banks are becoming more and more similar, and the loans to the new agricultural business entities are not very helpful.

\subsection{From the Perspective of Government Policy}

\subsubsection{Various policy systems are not sound}

First, the laws, regulations and policies related to financing are not perfect: my country lacks specific credit laws and regulations. The lack of relevant laws on private lending has made it difficult for private capital to be legally defined. As a result, private lending has always been in a state of scattered activities. The risks and interest rates of various new agricultural business entities through private lending are difficult to guarantee. Second, my country's national credit information system has not yet been fully constructed. The current national credit information system has established credit files for 184 million rural households and 2.61 million small and micro enterprises. However, my country has 226,290,104 ordinary farmers and 3,980,406 large-scale agricultural businesses. The base number is much more than. 
Therefore, banks and other financial institutions who want to understand the information of investigating new agricultural business entities often need to rely on traditional direct investigations or guarantee agencies to provide information, etc. The complicated and long steps and irregular processes can easily lead to financial institutions and new agricultural business entities. The problem of asymmetry between information. The business entity may also conceal corporate information due to its own development, and the bank cannot obtain the correct information from the information disclosed by the business entity, which leads to extremely asymmetric information between the bank and the enterprise. The third is the immature development of SME financing guarantee institutions led by the government. Lanxi City, Zhejiang Province currently has two government-led guarantee companies. As the main force in the agricultural guarantee project in Lanxi City, Lanxi Rural Credit Guarantee Company established the Provincial Farm Lanxi Agency in January 2019. The establishment time is still short. Exploration and pilot stage.

\subsubsection{Support policies need to be improved}

In recent years, my country has introduced many support policies, and the Lanxi local government has also increased support, such as tax reductions and exemptions, financial subsidies, etc., but most of them are support for listing of enterprises and small upgrades. On the one hand, due to the limited funds of local governments, the government still puts large and medium-sized state-owned enterprises and large-scale projects first in the order of lending. However, the emphasis on new agricultural business entities, especially family farms, is still low, and policy support is insufficient. Most of the support policies issued for new agricultural business entities were not implemented smoothly because of insufficient government funds. On the other hand, in recent years, along with a series of actions such as the information disclosure system, the "maximum run once policy", and digital reforms, most of Zhejiang Province supports agriculture. The performance of towns and villages below the county level is obvious. The six major agricultural production areas of Lanxi City are mainly distributed in the 6 sub-districts and 10 townships under its jurisdiction. There are many villages and complex industries, so policy disconnects often occur.

\subsubsection{Financial incentives and subsidies policy are supported}

In 2018, Zhejiang Province issued the "Implementation Opinions on Accelerating the Improvement of the Policy System for Cultivating and Supporting New Types of Agricultural Operation Subjects." Subsequently, the Jinhua and Lanxi levels issued corresponding policies on the one hand to provide financial subsidies in the form of awards for subsidies, construction first and then subsidies, and loan interest discounts for new agricultural business entities. On the other hand, the implementation of the targeted fee subsidy policy for rural financial institutions has provided 5 million yuan in agricultural loans to the city's five banking financial institutions with an increase of 284 million yuan and a small loan company's 116 million yuan in agricultural loans7. At the same time, actively leverage the advantages of policy-based financing guarantees, and actively integrate into the Zhejiang financial support agriculture ecosystem with the help of innovative pilot work. Provide financing support for new agricultural business entities through the coordination of the three parties of government and bank. However, with the end of the pilot work, a more complete and mature fiscal incentive policy is needed to take over the implementation.

\section{Solution Analysis}

\subsection{Actively Cultivate New Farmers and do a Good Job in Self-management}

The first is to build a training platform for professional farmers to cultivate professional skills, business management capabilities and financial knowledge. Only by optimizing agricultural varieties and brand building to improve product competitiveness can we find a place in the fiercely competitive market. Starting from the management concept, breaking traditional methods, introducing advanced and appropriate management concepts, and clarifying the intricate relationship of property rights. Improve financial systems and modern management systems to meet the credit conditions of financial institutions, establish financial awareness and trustworthiness, and cultivate friendly and cooperative relations between banks and enterprises. The second is to use platforms such as the Internet and universities. Expand the popularity of products and apply various innovative thinking and innovative technologies to operations. Only by achieving high-quality development and doing a good job of internal accumulation, can we still develop steadily even with insufficient external financing. Similarly, only companies with good growth potential can obtain financing in various ways from society.

\subsection{Improve the Financial Market System and Effectively Broaden Financing Channels}

First, financial institutions should investigate and understand the credit needs and operating conditions of business entities, closely follow up new agricultural entities, and implement list management. So as to launch targeted and innovative financial products, promote Internet finance, supply chain finance, and develop private equity funds to effectively meet the financing needs of business entities and broaden financing channels, and attract more private capital through demonstration effects. A promising new type of agriculture. The second is to set up specialized service agencies to adapt to the development of enterprises, adjust the direction of credit investment, and give prominence to local agricultural-related enterprises based on the characteristics of the operating entities. Develop inclusive finance for small and micro enterprises and agriculture, and cultivate its own financial support system for agriculture. The third is to introduce technologies such as the Internet, cloud computing, and blockchain throughout the entire loan process to vigorously carry out rural financial digital service management. Make good use of and promote the existing Xinnong Zhibao APP, 
the provincial rural credit guarantees company's big data management system and other new tools. At the same time, in the early, middle and late stages of management, financial institutions should establish risk identification functions, risk control index systems, and early warning mechanisms to achieve automatic and comprehensive monitoring.

\subsection{Increase Policy Guidance and Support to Create a Good Development Environment}

The formulation and implementation of government policies play a very important role in the business environment and financing environment of enterprises. From the central to the local level, the first is to pay attention to the financing environment of the new agricultural business entities. Chen Weidong and others have proposed to promote the establishment of urban and rural social credit information systems, improve the credit evaluation of farmers, and establish complete farmers' credit files[5]. Create a transparent and open credit information system to help build trust among stakeholders and provide support for lowering the barriers to entry for the capital market. The second is to improve the financial legal system, increase law enforcement, and do a good job in financial knowledge training. Regulate Internet finance, private lending, etc., and create a law-abiding financial environment. The third is to increase financial support, through the introduction of a series of corresponding preferential policies such as low interest, interest-free loans, taxes, water and electricity reductions, new technologies, and new varieties to help companies improve their competitiveness and increase corporate benefits. Support the Lanxi Rural Credit Guarantee Company under the leadership of the government, effectively solve the financing dilemma, and open up the "last mile" of financial support for agriculture. The fourth is to further resolve the issue of "two rights mortgage", improve the relevant legal system, and solve related issues such as rural housing mortgage. At the same time, it will expand the audience of farm tool mortgages, patents, brand mortgages, and order mortgages. Really realize a win-win situation where finance helps agriculture and agriculture boosts finance.

\section{References}

[1] Zhan Yan. Reasons for the formation of the financing dilemma of new agricultural business entities and solutions[J]. Journal of Xihua University (Philosophy and Social Sciences Edition), 2017, 36(04): 72-74+85.

[2] Zhou Mengliang, Chen Tinghui. Research on the Problems and Countermeasures of Family Farm Financial Support-Based on the Investigation of Linwu County, Hunan Province[J]. Economic Forum, 2015 (09): 64-68.

[3] Jonson, Bruce F, John Cownie. The Seed-fertilizer Revolution and Labor Force Absorption[J]. American Economic Review, 1969(4): 569-582.

[4] He Guangwen, He Jing. Financial needs in the revitalization of rural industries[J]. China Finance, 2019 (10): 33-34.

[5] Chen Weidong, Wei Gongkui, Liu Xuegui, He Yin. Practice and thoughts on solving the financing difficulties of new agricultural business entities-Taking Jinzhai County, Fengyang County, and Yongqiao District in Anhui Province as examples[J]. Rural work Newsletter, 2013 (02): 34-37.

[6] Li Runping. The era of diversified innovation in rural finance is approaching[N]. China Urban and Rural Finance News, 2017-08-02 (B02).

[7] $\mathrm{Wu} \mathrm{Yu,} \mathrm{Guo} \mathrm{Jiewen.} \mathrm{Rural} \mathrm{finance} \mathrm{enhances} \mathrm{services,}$ precise efforts to revitalize rural areas[J]. World of Finance, 2019(11):23

[8] Li Xiaohui, Xu Mingyuan. SWOT analysis of the financing of new agricultural business entities under the background of rural revitalization[J]. Journal of Electronic Engineering Institute, 2019, 8(10): 67-67.

[9] Li Tian. Research on the financing dilemma and countermeasures of Sichuan's new agricultural business entities from the perspective of rural revitalization[D]. Sichuan Provincial Committee Party School of the Communist Party of China, 2019.

\section{Author Profile}

Xichen Huang (1996-), Postgraduate of the School of Economics and Management, Zhejiang Ocean University. Born in Lanxi City, Zhejiang Province, with a professional name of Rural Development. 